${ }^{1}$ Universidade Estadual de Goiás.

E-mail:

camarals2013@gmail.com

Orcid:

https://orcid.org/0000-0001-5553-5238

\section{A REPRESENTAÇÃO SOCIAL DA DIGNIDADE DA PESSOA HUMANA NA VISÃO DO ACADÊMICO DA UNIVERSIDADE ESTADUAL DE GOIÁS - UEG}

\author{
THE SOCIAL REPRESENTATION OF THE DIGNITY OF THE HUMAN BEING \\ ACCORDING TO THE STUDENTS OF UNIVERSITY OF GOIÁS - UEG
}

Cynthia Santos ${ }^{1}$

Como citar: SANTOS, Cynthia. A representação social da dignidade da pessoa humana na visão do acadêmico da Universidade Estadual de Goiás - UEG. Revista do Instituto de Direito Constitucional e Cidadania - IDCC, Londrina, v. 6, n. 1, e022, jan/jun, 2021. ISSN: 2596-0075. DOI: 10.48159/revistadoidcc.v6n1.e022

Resumo: A pesquisa realizada sobre a Dignidade da pessoa humana, que está interligada a um Macroprojeto, cujo tema é a Constituição Federal, os Direitos Fundamentais e a Representação Social trouxe uma perspectiva na visão dos estudantes universitários e sua representação social. Foi estudado o princípio universal da dignidade, seu contexto histórico e conceitual. Na parte prática foi realizada uma entrevista para saber a representação social dos acadêmicos, dos cursos de Direito, Ciências Biológicas e Agronomia, da Unidade Palmeiras de Goiás da Universidade Estadual de Goiás. O estudo também analisou, utilizandose a teoria das Representações Sociais, qual o significado desse princípio para os estudantes dos cursos acima citados, tanto na perspectiva social, do ser humano em si, quanto na atuação do Estado, como cumpridor dos preceitos da Constituição Federal e como defensor do interesse público. O estudo realizado usou como metodologia uma pesquisa de caráter qualitativo e quantitativo, a pesquisa bibliográfica, que foi construída através das obras de grandes doutrinadores do direito, bem como os preceitos da própria Declaração dos Direitos do homem, documento instituído pela Organização das Nações Unidas - ONU, em 1948. Foi feito um levantamento amostral através da aplicação de um instrumento de coleta de dados, com a participação de 137 participantes divididos da seguinte maneira: 62 alunos do curso de direito, 40 alunos do curso de Ciências biológicas e por fim 35 alunos do curso de Agronomia. As contribuições científicas alcançadas com esse estudo foi o surgimento de uma suposta representação social dos acadêmicos em relação ao princípio da dignidade da pessoa humana. Através do levantamento de dados foi possível perceber que os acadêmicos têm uma percepção de que a dignidade se refere a cinco palavras, que foram mais evocadas por eles, "igualdade", "Respeito", "Direito", "Condições" e "Solidariedade". A partir desse resultado foi realizada uma análise e chegou-se à conclusão que os participantes do estudo creem que para que se haja dignidade é necessário ter igualdade, tratar todos em conformidade com a lei, em igualdade de condições. É preciso também respeitar os direitos e dar as condições mínimas que são necessárias para a manutenção da vida dos mais necessitados. A isso se conjuga a solidariedade, esta que deve partir do Estado, um dos objetivos da República Federativa do Brasil, mas também da sociedade, ou seja, é necessário ter uma sociedade justa e solidária.

Palavras-chave: dignidade; solidariedade; respeito; condições; igualdade. 


\begin{abstract}
The research accomplished about the dignity of the human being, interconnected to a Macroproject, which theme is the Federal Constitution, Fundamental Rights and Social Representation has brought a perspective in the view of the university students and their social representation. The universal principle of dignity, its historical and conceptual context were studied. In practical, an interview was carried out detect the social representation of academic people of Law, Biological Sciences and Agronomy courses, at Palmeiras de Goiás Unit at University of Goiás. The research also analyzed, using the Social Representations Theory, the meaning of this principle for the students of the courses mentioned, in the social perspective of the human being and also on the performance of the State, as the precepts fulfiller of the Federal Constitution and a defender of the public interest. The research used as a qualitative and quantitative research methodology, bibliographic research, built through the great legal scholars works, as well as the precepts of the Declaration of Human Rights, a document instituted by the United Nations - UN, in 1984. A data collection was also applied, taking part 137 individuals divided as follows: 62 students from the law course, 40 students from the biological sciences course and finally 35 students from the agronomy course. The scientific contributions achieved were the arise of a supposed academics social representation in relation to the human dignity principle. Through the data survey, it was possible to verify that academic ones own a perception that dignity is refered to five words, which were most evoked by them, "Equality", "Respect", "Law", "Conditions" and "Solidarity". From these words an analysis was carried out, concluding that the analysed people believe that in order to exist dignity, equality is needed, being treated in accordance to the law, under equal conditions. It is also needed respect the rights and the minimum conditions to be given to the most needy ones. This combined with solidarity, that should be provided by the State, one of the Federative Republic of Brazil's objectives, as well of the society, that means, it is needed to have a fair and solidary one.
\end{abstract}

Keywords: dignity; solidarity; respect; conditions; equality. 


\section{INTRODUÇÃO}

A presente pesquisa, cujo tema é a Representação Social da Dignidade Humana buscou refletir sobre esse princípio sob a ótica dos acadêmicos de três cursos superiores da Universidade Estadual de Goiás. A primeira parte delineou os contornos históricos e conceituais que especificam esse direito como uma condição mínima de existência para os cidadãos constitucionalmente consagrado.

É uma qualidade inerente, mas ao mesmo tempo distintiva em cada ser humano, que deve ser respeitado por parte do Estado. É um conjunto de normas que unidas impedem que haja arbítrio por parte do governo contra o cidadão. Pelo contrário a sociedade deve viver com qualidade de vida, e essas ações devem partir das ações estatais no sentido de proporcionar condições mínimas para uma existência saudável.

É um projeto de importância tanto para o ramo do direito, quanto para a psicologia social. Estudar a representação social de um grupo de sujeitos a respeito desse tema pode trazer conhecimentos científicos, filosóficos e ideológicos. Também é importante salientar que a partir das análises dos dados coletados, pode-se chegar ao senso comum dos alunos que representaram os seus envolvimentos com o princípio acima citado.

$\mathrm{O}$ artigo foi desenvolvido em duas partes. Primeiro a pesquisa bibliográfica em que se discutiu a respeito do conceito da dignidade como direito fundamental. A segunda parte referese a análise e discussão dos resultados gerados pelo Software Iramuteq, análise qualitativa e quantitativa. Foram entrevistados 137 sujeitos, acadêmicos de três cursos superiores da Universidade Estadual de Goiás - UEG, Unidade Palmeiras de Goiás, sendo eles: Direito, Ciências Biológicas e Agronomia.

O questionário utilizado para o desenvolvimento da pesquisa foi dividido em quatro partes. A primeira tratou o tema do direito fundamental utilizando-se a técnica da evocação, em que se pediu aos entrevistados que evocassem as cinco primeiras palavras que viessem a mente, quando ouvissem a expressão "Dignidade Humana". A segunda parte foram realizadas duas questões utilizando-se a escala Likert como parâmetro. As perguntas foram direcionadas para a legislação a respeito do tema no Brasil e se o Estado cumpre suas funções em relação aos cidadãos.

Também foi elaborada uma questão subjetiva para que o acadêmico respondesse em forma de texto, o que para ele significaria o princípio constitucional especificado. Os dados Sociodemográficos encerraram a pesquisa e se buscou saber sobre a idade, curso superior e 
período cursado. Foram realizadas 137 entrevistas, divididas nos três cursos superiores acima especificados.

É um direito fundamental ao ser humano e precisa ser respeitado pelo Estado. As funções estatais devem ser direcionadas para o interesse público, no sentido de cumprir as funções essenciais para resguardar vida digna e o mínimo existencial ao cidadão. Assim, essa pesquisa revelou que o cumprimento desse princípio por parte da Administração Pública irá assegurar o desenvolvimento saudável do indivíduo e da sociedade que sempre busca liberdade, solidariedade e qualidade de vida.

\section{O PRINCÍPIO DA DIGNIDADE DA PESSOA HUMANA}

Os direitos humanos, sendo esse um dos principais, tem que como finalidade viabilizar uma convivência harmônica, pacífica e produtiva entre todas pessoas que vivem em coletividade. É essencial para a formação de um Estado democrático de direito, pois sem esses direitos, que são basilares, podem acontecer revoluções, guerras e revoltas.

O homem primitivo, mesmo nos primórdios da sociedade, já buscava sua proteção individual. Quando racionalizava a sua comida e arrumava formas de se proteger das intempéries, como chuvas, morte de animais e etc. Bertrand Russel, citado por Maria Emilia Rocha de Melo Azevedo (1994, p.12) dizia que:

...quando um homem primitivo, nas brumas da pré-história, guardou um naco de carne para o dia seguinte depois de saciar a fome, aí estava nascendo a previdência. A previdência simplesmente. Daí para a previdência social foi apenas uma questão de técnica.

Russomano (1978) afirmou em seus estudos que não se tem como precisar quando se deu o início da previdência social, que hoje seria o equivalente ao princípio geral do ser digno. Não se sabe dizer se foi quando o homem começou a guardar o seu alimento para o dia seguinte ou quando começaram a surgir os primeiros sentimentos de solidariedade entre os homens, quando era pungente as aflições de alguns o que levava a solidariedade de tantos outros.

No decorrer da evolução histórica, Scarlet (2011), explica que se iniciou seu processo de manifestação no âmbito do pensamento jusnaturalista, séculos XVII e XVIII, que mantém a noção fundamental da igualdade de todos os homens em dignidade e liberdade. As primeiras manifestações, no âmbito constitucional desse princípio, em diversos Estados, remetem-se ao 
século XX, que foi incentivado pelos horrores registrados nas duas Grandes Guerras, principalmente a Segunda Guerra Mundial.

No Brasil, Cleber Francisco Alves (2001), analisou a Constituição do Império de 1824, que teve um papel bastante significativo no que se refere a normatização dos direitos fundamentais, mas deu destaque apenas a liberdade, segurança individual e a propriedade. Essa primeira Constituição ratificou os princípios da igualdade e legalidade, especificando que nenhuma lei poderia ser publicada em o caráter público, mas não fez menção expressa, ao direito estudado.

Somente a Constituição brasileira de 1934, trouxe em seu artigo 115, "a todos existência digna".

O princípio está previsto no artigo $1^{\circ}$, inciso III, da Constituição Federal e é um postulado central, fundamento da República Federativa do Brasil. É um parâmetro orientador que orienta todas as atividades estatais, inclusive a atuação dos três poderes, Legislativo, Executivo e Judiciário, bem como de todas as atividades privadas e atua como um piso protetivo mínimo.

\subsection{CONCEITO}

É uma palavra que possui vários significados, o sentido mais correlato é o “merecimento ético" e se baseia na honestidade e honradez. O princípio recebe um adjetivo "pessoa humana", que se refere a uma identificação jurídica baseada em critérios biológicos e filosóficos e faz a diferença entre máquinas, objetos inanimados e animais.

Essa adjetivação vem para demonstrar que é um atributo essencialmente humano, o que leva a crer que de forma automática qualquer ser humano é merecedor de respeito e proteção, sem distinção de raça, origem, credo, estado civil, bem como a condição socioeconômica.

Plácido e Silva (1967), explica que a palavra é originária do latim "dignitas", que significa virtude, honra, consideração, é na verdade a qualidade moral, possuída por uma pessoa que merece respeito. Os autores acrescentam ainda que se trata do próprio procedimento da pessoa pelo qual se faz merecedor no conceito da sociedade. No sentido jurídico representa a distinção ou a honraria que é conferida a um ser humano, pelo cargo ou título que lhe é conferido pela alta graduação, já no direito Canônico é o benefício ou prerrogativa de um cargo eclesiástico que se ocupa. 
O jurista Ribeiro Neto (2012) ao conceituar o princípio cita o filósofo Immanuel Kant (1724-1804), que inspirado pela obra de Jean Jacques Rousseau explica que cada ser tem a sua dignidade e ela não tem preço, pois cada ser humano é um fim em si mesmo. Por isso, ele fala que a razão orienta a vida moral, mas pautando-se no domínio da vontade livre, ou seja, na autonomia.

Kant, citado por Camargo (2007) desenvolve a ideia de que os seres humanos são igualmente dignos de respeito, sendo exatamente esse o traço distintivo do homem, de um ser emocional para um ser racional, o que demonstra que ele existe em si mesmo, por isso, não pode ser usado como um simples meio social, o que limita o uso arbitrário desta ou daquela vontade.

Dentre os doutrinadores brasileiros, Bulos (2017) afirma que a dignidade deve ser prioridade para o ser humano, isso porque é o espaço de integridade moral em que se alcança uma vitória contra a intolerância, a exclusão social e o preconceito. Na visão do autor é um conjunto de valores que são incorporador ao patrimônio do homem e que tem caráter civilizatório, pois seu conteúdo jurídico está interligado com o direito as liberdades, nos aspectos individuais, coletivos, políticos e sociais.

\section{DA TEORIA DA REPRESENTAÇÃO SOCIAL}

Moscovici (1982) idealizou o conceito de Representação Social como teorias, ou ciências coletivas, que de forma suigeneris, são as responsáveis pela interpretação e construção do real. São as ideias e valores que se apresentam e determinam campos possíveis de comunicação em grupos compartilhados, portanto, elas regulam as condutadas possivelmente desejáveis ou admitidas por aquele grupo de pessoas. Moscovici (1982), ainda acrescentava que para se compreender esse universo era necessário se verificar as dimensões latentes de sua construção.

Os estudos do idealizador da Teoria das Representações Sociais tiveram o mérito de propor uma noção em que o sujeito não é visto como um aparelho intrapsíquico, mas na realidade um produtor e produto de uma determinada sociedade, que recebeu o nome de Carrefour. Foi quando se abriu a perspectiva de se interligar conceitos de Sociologia com a Psicologia, em que a sociedade é um produto social, mas também é humano e leva a uma reconstrução e reelaboração do ser humano em sociedade (BERGER e LUCKMANN, 1973). 
A Representação Social é para Jodelet (1991) uma forma de conhecimento, que deve necessariamente ser tratada em processos e estudos diversos, enquanto saber prático que se revela através do senso comum e é socialmente compartilhado no quotidiano. Por isso, para a autora essa teoria envolve algumas condições que são: o sujeito revela seu conhecimento, em grupo ou individualmente, em sua experiência prática e depois se analisa as condições de sua produção.

Os estudos realizados utilizando-se a Teoria das Representações Sociais refletem sempre em um diversidade e contradição de conteúdos durante todo o processo. E esse processo não pode ser entendido apenas como coletânea de informações ou elaboração de teorias, mas sim, como prática cotidiana, o que significa que a criação e a manutenção de uma ordem social são funções básicas das representações.

A diversidade acima citada, e que está implícita no senso comum, não pode ser verificada isolando-se o consenso, pois esse também sustenta uma determinada ordem social, que se refletem em conhecimentos historicamente localizados e também ressonâncias do imaginário social. Morin (1983) ainda defende que no momento em que se dá o imprinting, o pensamento estruturado, pode haver zonas fracas, onde há uma abertura e que se permite movimento, mudanças que geram novidades àquela representação.

É importante destacar as funções das representações sociais que foram apresentadas por Abric (2000). A primeira a função de saber, a qual permite compreender a realidade e entender como os atores adquirem suas convicções práticas dentro do senso comum. A função identitária, segunda na classificação, como o próprio nome revela permite identificar a especificidade de cada grupo, social e pessoalmente, o que se torna compatível com os valores sociais e historicamente determinados.

A terceira função é a orientação refletindo que as representações são verdadeiros guias para os comportamentos dos sujeitos em grupo e as práticas obrigatórias, o que leva a definir o que é lícito, tolerável ou também inaceitável em um contexto social. Por fim, a quarta e última função, a justificadora, que faz o papel de justificar o porquê da tomada de posição e comportamentos compartilhados entre os sujeitos e o grupo ao qual ele pertence.

Para a elaboração de uma possível representação social, como foi postulado por Moscovici em 1961, existem dois processos envolvidos, primeiro a ancoragem e segundo a objetivação. Quando existe um pensamento que já está constituído na sociedade, mas há uma outra inserção orgânica, que lhe é estranho, há a manifestação do primeiro processo que é a ancoragem. Para Moscovici (1978) é uma verdadeira domesticação da novidade, nos valores 
antigos e reticentes, e que se torna capaz de influenciar outros grupos ou pessoas. O autor ainda acrescenta que a medida que essa mudança ancorou em uma camada social ela se torna capaz de influenciar, pois é feita, na verdade dessa realidade social vivida diariamente, e não pode ser concebida como processo de conhecimento individual.

Para a cristalização da representação entre em cena o segundo processo que é chamado por Moscovici (1988) de objetivação, que nada mais é do que uma operação formadora de imagens, no qual noções abstratas se transformam em algo concreto, tão vívidos na mente de um grupo. É um processo composto de três fases, sendo a primeira a descontextualização de um pensamento forma, pelos critérios normativos em como culturais; a segunda, momento no qual se forma figurativa de uma realidade conceitual, a imagem em si e a terceira em que acontece a transformação, imagens figuradas são naturalmente revertidas em elementos reais.

É importante para as pesquisas em representação social pois se entende que elas são essencialmente dinâmicas e produtos de determinações históricas, ou seja, conforme o momento em que se vive. São construções que tem a função primordial de orientar os conhecimentos que fazem com o que o indivíduo se situo no contexto da sociedade.

É uma teoria muito usada nas pesquisas em Ciências Humanas e Ciências Sociais aplicadas, ramo do curso de direito, e sempre se aponta um objeto novo de investigação. Estudase objetos específicos, tais como a Dignidade da Pessoa Humana, em que será possível fazer a percepção que os sujeitos informantes têm a respeito da questão proposta.

O conceito de dignidade e a sua importância como princípio é um fenômeno social que deve ser teorizado em sua melhor compreensão, que se investigue de forma crítica e reflexiva quais as representações dos participantes da pesquisa e como eles constroem esse objeto socialmente.

Outro ponto importante é um diálogo entre as várias áreas do conhecimento, para que ao analisar o objeto de estudo tenha vários pontos de vista e perspectivas, o que poderá levar a um sentido maior de totalidade, por isso, essa pesquisa procurou sujeitos das áreas da agronomia, biologia e direito, buscando conceitos e percepções diferentes entre os mais variados sujeitos. Resume-se que as sociedades são mutáveis e assim coexistem várias representações entre sujeitos diferentes.

A partir da teoria das representações sociais pode-se verificar quais os possíveis conhecimentos construídos a respeito de um determinado assunto, no caso da pesquisa proposta, a Dignidade da Pessoa Humana. É um assunto de extrema importância e que ajudará a verificar como o homem está construindo a sua percepção diante de si e também da sociedade. 


\section{INSTRUMENTO DA PESQUISA E MÉTODO}

A presente pesquisa é qualitativa e quantitativa e é orientada pela Teoria das Representações Sociais. Essa teoria possibilita ao pesquisador visualizar a interpretação dos participantes da realidade que se pretende estudar, o que gerou a possibilidade de se compreender atitudes e comportamentos de um grupo social escolhido entre alunos de três cursos superiores da Universidade Estadual de Goiás.

A amostra da presente pesquisa foi constituída por 137 alunos, de três cursos superiores, Ciências biológicas; Agronomia e Direito, da Unidade Palmeiras de Goiás. Foram entrevistados 62 alunos do curso de direito, do $2^{\circ}$ e $4^{\circ}$ períodos; 40 alunos do curso de Biologia, $6^{\circ}$ e $8^{\circ}$ períodos e 35 alunos do curso de Agronomia, distribuídos entre o $2^{\circ}$ e $5^{\circ}$ períodos.

Na coleta de dados foi utilizado um questionário composto de uma questão de evocação, usando como termo indutor "Dignidade humana". O aluno teria que especificar as cinco primeiras palavras que lhe vinham à mente, a respeito da expressão indutora e também justificar as duas primeiras palavras evocadas.

Foram feitas também, em um segundo momento, duas questões utilizando-se a escala Likert e uma questão subjetiva, em que se pediu ao aluno, que explicasse o que para ele significava a expressão "Dignidade da Pessoa Humana". Por fim, na segunda parte do questionário foram apresentadas questões sobre dados Sociodemográficos dos entrevistados. Os dados foram coletados em 2019. Para o tratamento dos dados foi utilizado o Software IRaMuTeQ, que foi desenvolvido por Pierre Ratinaud (2008), e que auxilia nas análises estatísticas sobre corpus textuais, e também sobre tabelas, participantes e palavras.

\subsection{DADOS SOCIODEMOGRÁFICOS}

A amostra da presente pesquisa foi constituída por 137 alunos, de três cursos superiores, Ciências biológicas; Agronomia e Direito, da UEG, Unidade Palmeiras de Goiás. Foram entrevistados 62 alunos do curso de direito, do $2^{\circ}$ e $4^{\circ}$ períodos; 40 alunos do curso de Biologia, $6^{\circ}$ e $8^{\circ}$ períodos e 35 alunos do curso de Agronomia, distribuídos entre o $2^{\circ}$ e $5^{\circ}$ períodos. Os dados Sociodemográficos da pesquisa foram especificados na seguinte ordem:

Quanto ao período cursado pelos acadêmicos, o maior percentual foi de alunos do quarto período do curso de direito. Ao todo foram 33 alunos que responderam a entrevista, que perfaz um percentual de $24,08 \%$ do total. O segundo maior percentual foi de acadêmicos do $3^{\circ}$ período 
do curso de direito, em que 32 alunos responderam ao questionário que equivale 23,35\%. O terceiro maior número de alunos concentrou-se no $5^{\circ}$ período de Agronomia, com 22 entrevistados e $16,05 \%$ do total.

Em relação a idade foram entrevistados alunos entre as idades de 18 anos até 70 anos de idade. Em percentual a grande maioria dos estudantes, total de 64,23\% equivalem a faixa etária entre 20 e 30 anos de idade. Com 17,51\%, 24 acadêmicos que responderam ao formulário estavam na faixa entre 15 e 20 anos. Com idades entre 40 e 50 anos, houve apenas 5 participantes, que equivale a um total de 3,64\%. O restante, apenas 3 alunos, entraram na faixa entre 51 a 60 anos e 61 a 70 anos, perfazendo apenas um total de 2,17\%.

No âmbito geral dos entrevistados, responderam o questionário 83 mulheres, que equivale a 60,58\% e 54 homens que equivale a $39,41 \%$ do total. Já em relação ao curso de graduação a que pertencem, a grande maioria, no total de 113 alunos pertencem ao curso de Direito, que equivale a 82,5\%. Do curso de agronomia participaram apenas 19 alunos, 13,86\% e em menor número 5 alunos do curso de Ciências biológicas, que equivale a 3,64\%.

\section{DiscuSSÃo e RESUlTADOS}

A quarta parte do trabalho fará a discussão dos resultados quantitativos e qualitativos analisados pelo programa Software IRaMuTeQ, através da explicação a luz do direito em relação as palavras evocadas pelos sujeitos da pesquisa.

\subsection{ANÁLISE DAS FREQUÊNCIAS}

Utilizando-se a análise de frequência do programa Iramuteq foi detectado quatro palavras repetidas várias vezes, sendo elas: respeito; condições; direito e solidariedade, em que se atingiu conforma tabela 1 abaixo os seguintes percentuais.

Tabela 1. Palavras mais evocadas e percentual de evocação

Palavra evocada

\begin{tabular}{ccc} 
Palavra evocada & Percentual & Média de evocação \\
\hline Igualdade & $14,78 \%$ & 81 vezes \\
\hline Respeito & $10,04 \%$ & 55 vezes \\
\hline Direito & $10,04 \%$ & 55 vezes \\
\hline Condições & $7,12 \%$ & 39 vezes \\
\hline Solidariedade & $4,2 \%$ & 23 vezes
\end{tabular}

Fonte: elaborada pela autora. 
As palavras mais evocadas, que possivelmente fazem parte da centralidade da representação social percebida pelos alunos entrevistados foram, na sequência conforme apresentado na tabela 01: "Igualdade", 81 evocações; "respeito", 55 repetições; “direitos" com média de frequência de 55 evocações, “condições” com 39 evocações, e por fim "Solidariedade com 23 repetições.

Essa amostra leva a uma possível representação por parte dos alunos dos cursos de Ciências biológicas, Agronomia e Direito, nos seguintes aspectos. No percentual de quase 15\% dos entrevistados, têm uma percepção de Dignidade voltada para o alcance da igualdade entre as pessoas, preceito constitucional do artigo $5^{\circ}$, caput, bem como do inciso $1^{\circ}$ do mesmo artigo. Só se conseguirá promover a Dignidade do ser humano, quando de forma verdadeira se conquistar a igualdade entre todos.

Outra palavra que teve seu destaque foi "respeito", ou seja, para o acadêmico, além da igualdade é necessário que haja respeito para com o ser humano. Quando se reflete sobre valores humanos, dignidade das pessoas, o respeito se torna um dos temas mais importantes, pois é essencial para uma boa interação social. Com respeito qualquer pessoa é impedida de cometer atos perigosos contra seu semelhante, pois surge empatia por alguém ou algo.

Respeito e dignidade são considerados essenciais para criar um ambiente para as pessoas e garantem que a partir dessa união sejam criadas comunidades unidas, em que se vislumbra um futuro repleto de oportunidade e principalmente de esperança. Assim, o acadêmico também reflete nessa necessidade de que essas duas palavras andem juntas, porque somente assim, se abrirá portas para que o ser humano viva uma vida digna em todos os aspectos.

A terceira palavra mais evocada é "Direito", que para Miguel Reale (1995), refere-se aos olhos do homem a lei e a ordem, que é simbolizado por um conjunto de normas e regras obrigatórias e que devem ser respeitadas para a boa convivência social. Essa exigência é para que haja o estabelecimento de limites à ação de cada um de seus membros. Percebe-se assim, que para os acadêmicos entrevistados, 10,04\% a dignidade vem do respeito as normas que são impostas pelo poder competente e a partir do momento em que essa lei é usada e respeitada pelo ser humano ou pelo Judiciário quando da aplicação das normas ao caso concreto, se faz justiça que é uma forma de se conceder a dignidade a sociedade.

Já "Condições" foi a quarta palavra mais evocada pelos acadêmicos entrevistados. Os alunos representam a dignidade da pessoa humana ao alcance do mínimo de condições para a sobrevivência do ser humano. O princípio da dignidade está no título dos direitos fundamentais, no campo dos direitos sociais da Constituição Federal de 1988 em que se especifica as 
condições materiais mínimas do homem, como saúde, educação, trabalho, previdência, moradia e tantos outros. Quando esses direitos não são fornecidos há um prejuízo no exercício da liberdade, não há proteção ativa da vida humana o que leva a não se ter dignidade.

Por fim, a palavra solidariedade teve seu destaque e possivelmente faz parte da representatividade dos acadêmicos em relação a dignidade da pessoa humana. A palavra solidariedade aparece no artigo $3^{\circ}$ da Constituição Federal quando é especificado os objetivos fundamentais da República Federativa do Brasil, sendo um deles construir uma sociedade livre, justa e solidária.

Percebe-se que para os alunos essa palavra não pode estar dissociada do ideal da execução de políticas públicas para debelar a pobreza e a marginalização, pois são essas que podem fazer diminuir as desigualdades sociais e regionais, que significa mínimas condições e dignidade. A sociedade tem que se formar solidária e se tornarem responsáveis pelo bem comum, o que pode levar a crer que os sujeitos da pesquisa acreditem que eles podem fazer o que o Estado não faz.

\subsection{ANÁLISE TEXTUAL}

No questionário utilizado na presente pesquisa vou formulada uma pergunta subjetiva, qual seja: "Para você o que significa o direito a Dignidade da pessoa humana". No corpus textual tiveram 20 textos, com 58 segmentos e 504 formas. As ocorrências de palavras chegaram a um total de 1917, com 325 formas ativas. A partir das ocorrências o programa chegou a seis classes de palavras.

Para a discussão dos resultados foi o utilizado o Método de Reinert, que revelou o seguinte dendograma, figura 1 , a as palavras relacionadas figura 2. 
Figura 1. Dendograma de classes

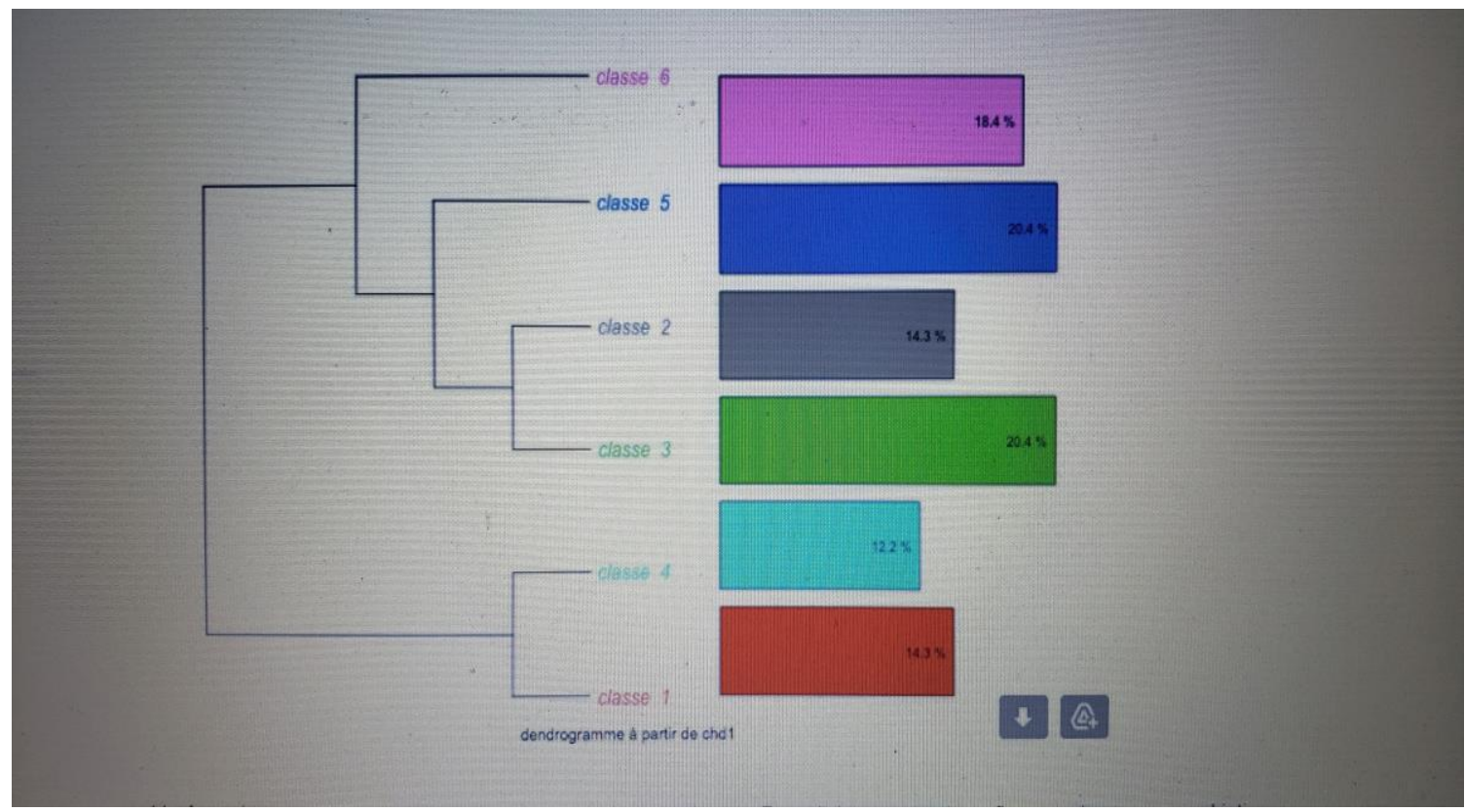

Fonte: elaborada pela autora.

O dendograma gerou seis classes de palavras, estando as mesmas distribuídas da seguinte forma: A classe 1 e 4 representadas respectivamente pelas cores vermelho e azul claro estão interligadas entre si e o tronco principal delas conecta-se com a classe 6 e 5, respectivamente destacadas pelas cores rosa e azul escuro. Na primeira classe as palavras que apareceram as palavras "valor", "moral", “inerente", "espiritual " e "respeitado". A partir da mesma origem o bloco 4 traz vocábulos que se interligam aos encontrados no primeiro bloco, sendo eles: "social", “individuo", "sociedade”, "igualdade", "respeito".

A análise indica que para os sujeitos entrevistados a dignidade é um valor que já nasce com o ser humano, faz parte da sociedade e deve ser respeitada. É um valor moral e espiritual que merece o devido respeito e deve ser concedido de forma igualitária a todos indistintamente.

As classes 1 e 4 estão relacionadas com a classe 6, que trouxe a seguinte relação de palavras: "saneamento", "igual”, “educação", "tratado", "passar”, “moradia”, "saúde”, "muito", "lei" e "lazer" Apesar de ser um valor ele tem que ser concedido de forma igualitária e sempre buscando a sociedade. Diante desse aspecto para se ter dignidade significa ter qualidade, e essa se conquista com uma boa atuação estatal na educação, saúde, moradia, que são preceitos legais e devem ser cumpridos.

A classe 6 tem estreita relação com o bloco 5, que especificou em destaque: "segurança", "educação", "liberdade", "dever", "saúde", "fundamental", "sobrevivência" e "existência". Essas duas categorias se interligam, mostram que o princípio da dignidade é fundamental e para que o mesmo exista é necessário que seja um dever legal que deve ser cumprido para conceder 
a população o mínimo necessário para sua sobrevivência. Essas ações também pertencem a esfera da segurança, ao mesmo tempo que como direito dá liberdade ao cidadão, o que freia um possível arbítrio por parte do Estado.

Por fim, a classe 5 está conectada com a 2 e a 3 que revelam as seguintes palavras em conjunto: “mínimo", “dignidade”, “necessário”, “vida”, "possibilidade”, "básico”, “condição”, "humano", "sempre”, “construir", "lei”, “pessoa”. Essas duas últimas classes se conectam as demais, tanto através de um tronco secundário como principal. Refletem que a dignidade é necessária e deve ser construída pelo Estado. Através das ações estatais e cumprindo a lei, devese sempre buscas suprir, mesmo que minimamente, as necessidades básicas da população, dando condições e possibilidade de sobrevivência.

\section{Figura 2. Plano cartesiano}

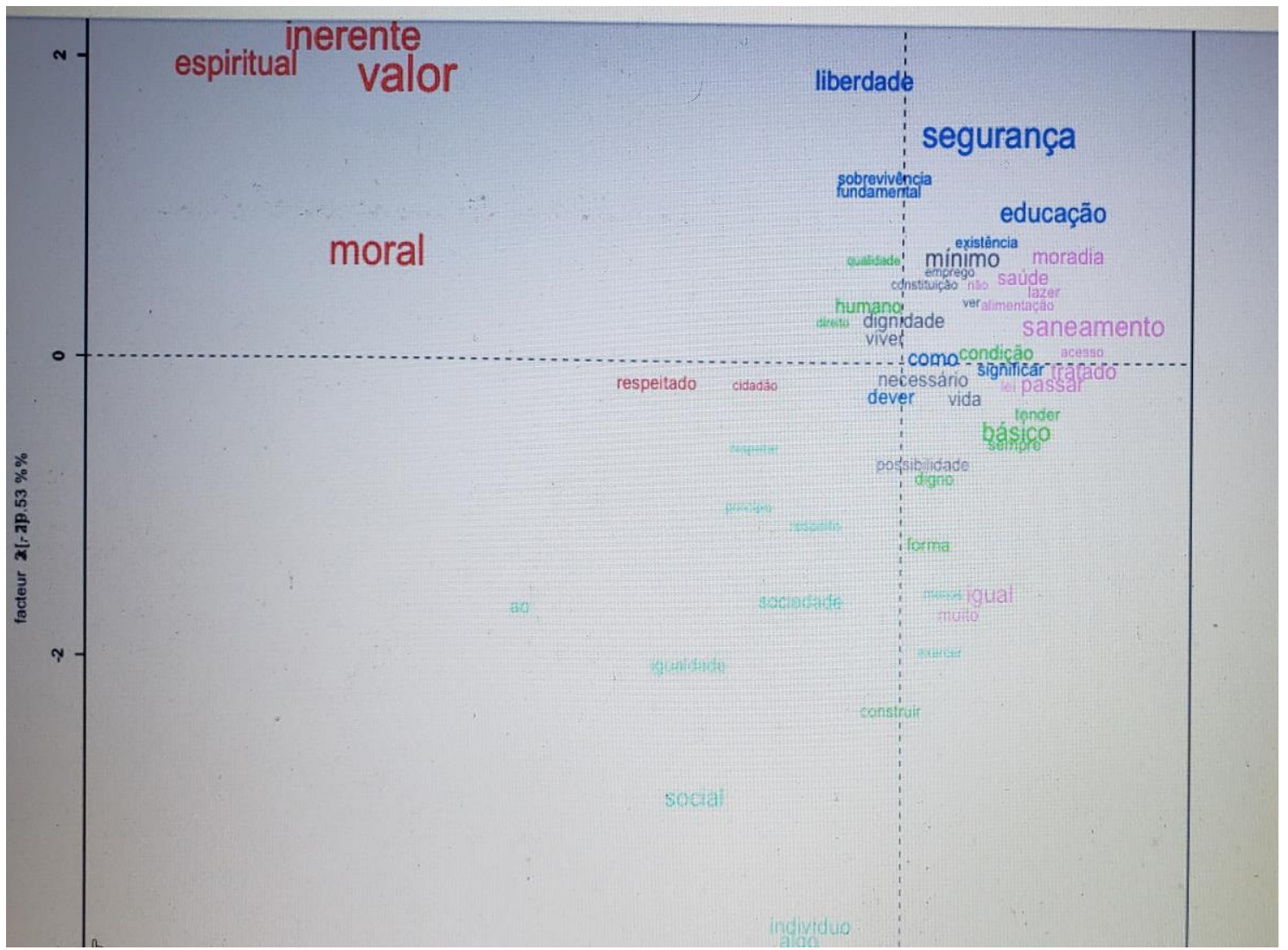

Fonte: elaborada pela autora.

No plano cartesiano, figura 04 , o que se percebe é o valor moral da dignidade sendo colocado longe da realidade que deve ser preservada. Esse princípio apesar de nascer com o ser humano, tem que ser resguardo pela lei e pelo Estado, função primária e básica, defender os interesses da população. Aglomerados no canto esquerdo surgem as palavras que dão sustentação a análise. O direito fundamental "Dignidade da pessoa humana" significa 
segurança, educação, liberdade, sobrevivência, ou seja, são as regras constitucionais que servem ao cidadão e devem ser a eles direcionados diariamente para que realmente esse princípio possa existir.

\section{CONSIDERAÇÕES FINAIS}

A pesquisa sobre o princípio da dignidade da pessoa humana revelou que o mesmo tem o condão de assegurar o desenvolvimento saudável do indivíduo e da sociedade, desde que se respeite a liberdade, a solidariedade, o direito e que tenha respeito pelas pessoas que estão convivendo juntamente com qualquer ser humano individualmente.

A igualdade foi outro ponto de destaque representado pelos sujeitos da pesquisa. Para os acadêmicos esse direito fundamental deixará de ser apenas uma palavra quando houver observância da igualdade, ou seja, quando todos poderem ser tratados de forma igual, não podendo existir uma diferenciação jurídica sem que exista um fundamento razoável.

Ela tem que ser equalizada aos interesses da sociedade, equilibrando direitos, deveres e respeito, sempre se voltando para o interesse público. Quando se une o princípio da solidariedade, com o respeito e as condições mínimas que devem partir das ações do Estado e do povo, para com seu semelhante, chega-se ao objetivo comum que é conferir o mínimo digno e cumprir os preceitos constitucionais. Assim se cumprirá o objetivo de se ter uma sociedade brasileira justa e solidária.

O acadêmico diz que a dignidade existe quando há respeito ao direito, que nada mais é a aplicação das normas jurídicas, o respeito às leis. Em todas as condições o ser humano deve ser tratado com um ser digno, e não como um simples objeto.

$\mathrm{Na}$ análise textual chegou-se à conclusão de que apesar de traduzido como um valor moral, pois pessoas nascem dignas e já possuem dignidade, para que as mesmas se mantenham sendo assim, necessário a atuação do Estado. Vive-se em um mundo e em um país em que a desigualdade social é discrepante.

A dignidade está incorporada aos direitos fundamentais e passou por um processo de democratização para dar uma dimensão igualitária a toda a sociedade. O importante a se perceber é que esse conceito volte aos primórdios, na forma original, onde ocupava um lugar mais elevado, com distinção merecida, respeito e com os direitos sendo resguardados de forma geral as pessoas. 


\section{REFERÊNCIAS BIBLIOGRÁFICAS}

ABRIC, J. C. Prefácio. In: SÁ, C. P. Núcleo central das representações sociais. Petrópolis: Vozes, p.7-9, 2000.

AZEVEDO, Maria Emília Rocha de Mello. A Previdência Social e a Seguridade Social. In: AZEVEDO, Maria Emília Rocha de Mello. A Previdência Social e a Revisão

Constitucional. Brasília: CEPAL; Ministério da Previdência Social, 1994, p. 12.

Berger, P. e Luckmann. T. (1973) A Construção Social da Realidade. Rio de Janeiro: Vozes.

BULOS, Uadi Lammêgo. Curso de Direito Constitucional. 3. ed. São Paulo: Saraiva, 2017.

Camargo, A. L. C. (2007). A dignidade da pessoa humana no direito brasileiro. São Paulo: Cultural Paulista.

MOSCOVICI, S., 1978. A Representação Social da Psicanálise. Rio de Janeiro: Zahar. , 1988. Notes towards a description of social representations. European Journal of Social Psychology, 18: 211-250.

MOSCOVICI, S. (1982) The comming era of social psychology. In J.P. Codol e J.P. Levens. Cognitive Approaches to Social Behavior. The Hagne, Nighoff.

MORIN, E., 1983. O Problema Epistemológico da Complexidade. Lisboa: EuropaAmérica.

REALE, Miguel. Lições Preliminares de Direito. 22a ed. São Paulo. Saraiva. 1995. Ribeiro Neto, J. C. (2012). Dignidade Humana (Menschenwürde): evolução históricofilosófica do conceito e de sua interpretação à luz da Jurisprudência do Tribunal Constitucional Federal alemão, do Supremo Tribunal Federal e do Tribunal Europeu de Direitos Humanos. Universidade Católica de Brasília.

RUSSOMANO, Mozart Victor. Curso de Previdência Social. 2a Edição. Rio de Janeiro: Editora Forense, 1978, p. 02.

SARLET, Ingo Wolfgang. Dignidade (da Pessoa) Humana e Direitos Fundamentais na Constituição Federal de 1988. Porto Alegre: Livraria do Advogado Editora, 2011. 